\title{
Synthesis and Characterization of Phase Pure NiO Nanoparti- cles via the Combustion Route using Different Organic Fuels for Electrochemical Capacitor Applications
}

\author{
G. Srikesh and A. Samson Nesaraj* \\ Department of Chemistry, School of Science and Humanities, Karunya University, Coimbatore - 641 114, Tamil Nadu, India.
}

\begin{abstract}
Transition metal oxide nanocrystalline materials are playing major role in energy storage application in this scenario. Nickel oxide is one of the best antiferromagnetic materials which is used as electrodes in energy storage devices such as, fuel cells, batteries, electrochemical capacitors, etc. In this research work, nickel oxide nanoparticles were synthesized by combustion route in presence of organic fuels such as, glycine, glucose and and urea. The prepared nickel oxide nanoparticles were calcined at $600^{\circ} \mathrm{C}$ for $3 \mathrm{~h}$ to get phase pure materials. The calcined nanoparticles were preliminarily characterized by XRD, particle size analysis, SEM and EDAX. To prepare nickel oxide electrode materials for application in supercapacitors, the calcined $\mathrm{NiO}$ nanoparticles were mixed with di-methyl-acetamide and few drops of nafion solution for 12 to $16 \mathrm{~h}$. The above slurry was coated in the graphite sheet and dried at $50^{\circ} \mathrm{C}$ for 2 to $4 \mathrm{~h}$ in a hot air oven to remove organic solvent. The dried sample was subjected to electrochemical studies, such as cyclic voltammetry, AC impedance analysis and chrono-coulometry studies in $\mathrm{KOH}$ electrolyte medium. From the above studies, it was found that nickel oxide nanoparticles prepared by combustion synthesis using glucose as a fuel exhibited resulted in low particle diameter (42.23 nm). All the nickel oxide electrodes have shown better good capacitance values suitable for electrochemical capacitor applications.
\end{abstract}

Keywords: Nickel oxide nanoparticles, combustion route with different organic fuels, physical characterization, electrochemical studies, electrochemical capacitors

Received October 17, 2014 : Revised October 21, 2014 : Accepted October 31, 2014

\section{Introduction}

One of the major challenges, the world recently facing is energy consumption and demand. To meet the energy requirements of this modern generation, an ideal energy storage device is needed at present to provide high energy in short time. Especially, the device should store more power and deliver high energy output for various applications. Among all other energy storage devices, electrochemical capaci- tors exhibit high power density than other electrochemical devices, such as batteries, photo-voltaic devices, etc. and high energy density than conventional capacitors because of unique charge storage mechanisms.

Depending on the charge storage mechanisms, the electrochemical capacitors can be categorized into two types, (i) electrochemical double-layer capacitors, mainly focusing on carbon materials in which the capacitance evolves from the charge separation at

*Corresponding author. Tel.: +091-422-2614485

E-mail address: drsamson@karunya.edu

Open Access DOI: http://dx.doi.org/10.5229/JECST.2015.6.1.16

This is an Open Access article distributed under the terms of the Creative Commons Attribution Non-Commercial License (http://creativ ecommons.org/licenses/by-nc/3.0/) which permits unrestricted non-commercial use, distribution, and reproduction in any medium, provided the original work is properly cited. 
the electrode and electrolyte interface; and (ii) pseudocapacitors, mainly concentrating upon conducting metal oxides and polymers which utilize the charge transfer pseudo-capacitance arising from reversible Faradaic reaction occurring at the electrode surface within the active electrode materials [1]. The electrode material is a main component in electrochemical capacitors because it determines the electrochemical performance of any full scale commercial ultra capacitors [2]. The common electrode materials which are recently use in electrochemical capacitors are carbon, transition metal oxides and conducting polymers. Nanostructured materials are gaining a great interest due to their wide applications in various fields such as lithium-ion batteries [3-5], ion exchange membranes [6], catalysis supports [710], solar cells [11] and supercapacitor electrodes [12-17].

Transition metal oxide nanocrystalline materials have been studied by several researchers due to their excellent properties. Transition metal oxides such as nickel oxide [18-19], ruthenium oxide [20-22], manganese oxide [23-25], cobalt oxide [26-28], etc. have been studied by various groups to obtain high specific capacitance and high charge/discharge ability in electro-chemical capacitors. Among the transitional metal oxides available, nickel oxide is an attractive material in various applications such as gas sensors [30], magnetic materials [31-33], catalysis [34], electrochromic applications [35] and electrode material [36-45] in electrochemical devices. In this research work, nickel oxide nanoparticles have been prepared by combustion route using different organic fuels, viz., glycine, glucose and urea. It was reported that organic fuels can play an efficient role in the wet chemical synthesis of nanocrystalline materials having uniform particle size distribution and excellent morphological characteristics [29]. The prepared nickel oxide materials were systematically characterized by XRD, particle size analysis, SEM and EDAX. After the preliminary characterization, the nanomaterials were utilized to fabricate electrodes and subjected to electrochemical studies, such as, cyclic voltammetry, AC - impedance analysis and chrono-coulometry studies. The obtained results were discussed and presented in this research article. Also, the effect of fuels in the performance characteristics of nickel oxide electrode for application in electrochemical capacitors is correlated and reported.

\section{Experimental}

\subsection{Synthesis and physical characterization of nickel oxide nanoparticles}

The synthesis of nickel oxide nanoparticles was carried out by using combustion route. The nickel nitrate (98\%, Loba chemie), glycine (98\%, Spectrum), glucose (99\%, Merck) and urea (99.5\%, Merck) were as used without any further purification. Nickel oxide nanoparticles have been prepared by solution combustion route using glycine, glucose and urea as fuels.

In a typical experiment, stoichiometric amounts of nickel nitrate $(2.9 \mathrm{~g})$ was dissolved in a minimum quantity of distilled water (approximately, $20 \mathrm{~mL}$ ) along with appropriate quantity of glycine $(0.83 \mathrm{~g})$ or glucose $(0.75 \mathrm{~g})$ or urea $(0.99 \mathrm{~g})$. The organic compounds are acting as a fuel and a complexant during the reaction. The complexation of metal ion by the fuel molecule increases the solubility of metal ions in solution. A stoichiometric composition denotes a fuel to metal nitrate ratio at which the fuel can react completely with the metal nitrate in the mixture, in such a way that no residual fuel or nitrate remains in the product materials. Based on propellant chemistry, the stoichiometric compositions of the redox mixtures for the combustion were calculated using the total oxidizing $(\mathrm{O})$ and reducing $(\mathrm{F})$ valencies of the components which serve as the numerical coefficients for the stoichiometric balance, so that the equivalence ratio, $\Phi_{c}($ i.e., O:F $=1$ ) is unity and the energy released by the combustion is maximum. Based on the propellant chemistry, the species, $\mathrm{Ni}^{2+}, \mathrm{C}$ and $\mathrm{H}$ are considered to be reducing species with corresponding valencies $+2,+4$ and +1 . Elemental oxygen is considered to be an oxidizing species with valency -2 . The valency of nitrogen is considered to be zero [29]. Based on these considerations, nickel nitrate will have oxidizing valency of -10 . The fuels such as, glycine, glucose and urea should have the reducing valencies of $+9,+6$ and +25 respectively. The mixed solution metal nitrate and fuel was heated in a mantle at $50-70^{\circ} \mathrm{C}$ and the volume was reduced as half. Afterwards, the resulting clear solution was introduced into a muffle furnace maintained at $600^{\circ} \mathrm{C}$. Initially the solution boils and undergoes dehydration followed by decomposition with evolution of large amounts of gases $\left(\mathrm{N}_{2}\right.$ and $\left.\mathrm{CO}_{2}\right)$. The mixture then froths and swells, forming a foam which ruptures 
with a flame and glows to incandescence. During the incandescence the foam further swells to the capacity of the crucible. The gases evolved not only helped to yield fine-particles of $\mathrm{NiO}$ but also help to dissipate the heat which inhibits sintering of the product. Thus, combustion reaction was completed within a few seconds, giving rise to a dark green coloured ash material that easily crumbled into powders. The flame persisted for about 1 minute. The foam was them lightly ground in glass mortar with pestle to obtain fine nanoparticles. The method exploits an exothermic, usually very rapid and self-sustaining chemical reaction between the metal nitrate and organic fuel which is ignited at a temperature much lower than the actual phase transformation temperature. Its key feature is that the heat required to drive the chemical reaction and accomplish the compound synthesis is provided by the reaction itself and not by an external source. The stoichiometric redox reactions between nickel nitrate and glycine or glucose or urea to produce nickel oxide can be represented by the following theoretical equations.

To prepare $\mathrm{NiO}$ by combustion technique with glycine as a fuel:

$$
\begin{aligned}
& \mathrm{Ni}\left(\mathrm{NO}_{3}\right)_{2}+1.11 \mathrm{NH}_{2} \mathrm{CH}_{2} \mathrm{COOH} \\
& \rightarrow \mathrm{NiO}+2.22 \mathrm{CO}_{2}+1.555 \mathrm{~N}_{2}+2.775 \mathrm{H}_{2} \mathrm{O}
\end{aligned}
$$

To prepare $\mathrm{NiO}$ by combustion technique with glucose as a fuel:

$$
\begin{aligned}
& \mathrm{Ni}\left(\mathrm{NO}_{3}\right)_{2}+0.42 \mathrm{C}_{6} \mathrm{H}_{12} \mathrm{O}_{6} \\
& \rightarrow \mathrm{NiO}+2.52 \mathrm{CO}_{2}+\mathrm{N}_{2}+2.52 \mathrm{H}_{2} \mathrm{O}
\end{aligned}
$$

To prepare $\mathrm{NiO}$ by combustion technique with urea as a fuel:

$$
\begin{aligned}
& \mathrm{Ni}\left(\mathrm{NO}_{3}\right)_{2}+1.66 \mathrm{NH}_{2} \mathrm{CONH}_{2} \\
& \rightarrow \mathrm{NiO}+1.66 \mathrm{CO}_{2}+2.66 \mathrm{~N}_{2}+3.32 \mathrm{H}_{2} \mathrm{O}
\end{aligned}
$$

Stoichiometric mixtures are reported to produce maximum energy in propellant systems. The mechanism of the combustion reaction is quite complex. The parameters which influence the reaction include type of fuel, fuel-to-oxidizer ratio, use of excess of oxidizer, ignition temperature and water content of the precursor mixture. In general, a good fuel should react nonviolently, produce nontoxic gases, and act as a complexant for metal cations. Complexation increases the solubility of metal cations, thereby preventing preferential crystallization as the water in the precursor solution evaporates. However, the redox mixtures containing metal nitrates and organic fuel undergo a smooth combustion reaction to yield the fine metal oxides. Calcination of as-synthesized powder was carried out in silica crucibles at $600^{\circ} \mathrm{C}$ for 3 hours in air to remove the deposited carbon and unreacted organic residues and to get phase pure material.

The powder XRD study was carried out using a Shimadzu XRD6000 X-ray diffractometer at a scan speed of $5 \mathrm{deg} / \mathrm{min}$ using CuKa radiation. The crystallite sizes have been calculated by Scherrer's equation [40]. The equation is mentioned below (1).

$$
D=z \frac{C \lambda}{\beta \cos \theta}
$$

where ' $D$ ' is the crystallite size, ' $C$ ' is the numerical constant ( $\sim 0.9)$, ' $\lambda$ ' is the wavelength of $x$-rays (for $\mathrm{CuK} \alpha$ radiation, $\lambda=1.5418 \AA$ ), ' $\beta$ ' is the effective broadening taken as a full width at half maximum (FWHM) (in radians), ' $\theta$ ' is the diffraction angle for the peak. The theoretical density $\left(\mathrm{T}_{\mathrm{d}}\right)$ was calculated using the equation (2).

$$
T_{d}=z \frac{M}{N \times V}
$$

where ' $z$ ' is the number of chemical species in the unit cell, ' $M$ ' is the molar mass of the single chemical species corresponding to chemical formula $\left(\mathrm{gmol}^{-1}\right)$, ' $V$ ' is the unit cell volume $\left(\AA^{3}\right)$ and ' $N_{A}$ ' is the Avogadro's number $\left(6.022 \times 10^{23} \mathrm{~mol}^{-1}\right)$.

The particle size of the powder was measured using a Malvern particle size analyzer (Malvern Instruments, Worcestershire, UK) using triple distilled water as medium. The morphology of the particles and percentage of elements present in the samples (EDAX) were studied by means of JEOL Model JSM-6360 scanning electron microscope (JEOL Ltd., Tokyo, Japan).

\subsection{Fabrication of nickel oxide electrodes and their electrochemical characterization}

To fabricate the nickel oxide electrode materials, the calcined individual nanoparticles (prepared by using three organic fuels) were mixed separately with di-methyl-acetamide (99\% purity, Loba chemie) and few drops of nafion (5 wt.\%, Sigma Aldrich) solution. Then, the mixture was stirred in a magnetic stir- 
rer for about 12 to $16 \mathrm{~h}$ to ensure homogeneity. The slurry was then coated with a doctor's blade on a thin graphite (having specific area of $1 \times 1 \mathrm{~cm}^{2}$ ) sheet. The fabricated electrodes were then dried at $50^{\circ} \mathrm{C}$ for about 2 to $4 \mathrm{~h}$ in order to remove the organic solvents present in the micropores of the electrodes. The weight of the active material present in each electrode samples was measured which was found to be around $0.005 \mathrm{~g}$. The electrochemical studies such as cyclic voltammetry, AC impedance analysis and chrono-coulometry studies were carried out with three electrode system having the fabricated electrode as a working electrode, platinum wire as a counter electrode and saturated calomel electrode as a reference electrode in $\mathrm{KOH}$ (1 M) electrolyte medium. The specific capacitance (C) of the individual electrode from cyclic voltammetry can be calculated from the following equation (3).

$$
\text { Specific capacitance }(C)=\frac{I}{(d V / d t) m}
$$

where ' $I$ ' is the current in A which is calculated from using the following formula (4):

$$
\text { Current }(C)=\frac{\text { Anodic current }- \text { Cathodic current }}{2}
$$

' $d V / d t$ ' denotes the scan rate in $\mathrm{mVS}^{-1}$ and ' $\mathrm{m}$ ' is the mass of the electrode $[26,42,46]$. From impedance studies, the specific capacitance (C) [equation 5] can be derived from the imaginary part $\left(Z^{\prime \prime}\right)$ of the impedance as per the literature [34].

$$
C=\left|\frac{1}{\omega Z^{\prime \prime}}\right|
$$

where ' $\omega$ ' denotes the angular frequency of the applied AC-signal. Based on the charge / discharge phenomena from chronocoulometry analysis, the specific capacitance for the electrode materials was measured on a single step process from the equation (6)

$$
C=\frac{Q}{V}
$$

where ' $Q$ ' is the charging current (in coulombs) and ' $V$ ' is the applied voltage (in volts).

\section{Results and Discussion}

\subsection{XRD studies}

Figure $1(\mathrm{a}, \mathrm{b}$ and $\mathrm{c})$ shows the XRD pattern for the $\mathrm{NiO}$ nanoparticles prepared by combustion technique using three organic fuels, glycine, glucose and urea respectively. The obtained sharp peaks in the XRD patterns show the crystalline behavior of the materials due to high temperature heat treatment car-

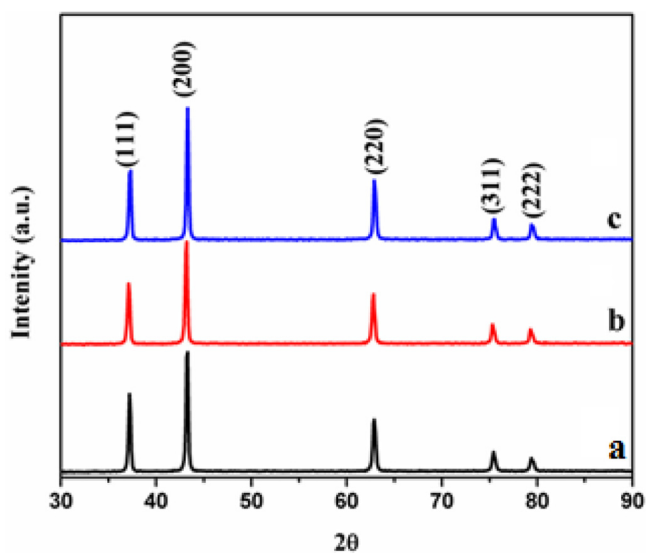

Figure 1. XRD pattern obtained on $\mathrm{NiO}$ nanoparticles prepared by combustion technique using three organic fuels, glycine (a), glucose (b) and urea (c).

Table 1. Crystallographic parameters obtained on nickel oxide nanoparticles

\begin{tabular}{ccccccc}
\hline Sample & Organic Fuel & $\begin{array}{c}\text { Crystal } \\
\text { structure }\end{array}$ & $\begin{array}{c}\text { Unit Cell } \\
\text { parameter 'a' }(\AA)\end{array}$ & $\begin{array}{c}\text { Unit cell volume } \\
\left(\AA^{3}\right)\end{array}$ & $\begin{array}{c}\text { Crystallite size } \\
(\mathrm{nm})\end{array}$ & $\begin{array}{c}\text { Theoretical density } \\
(\mathrm{g} / \mathrm{cc})\end{array}$ \\
\hline $\begin{array}{c}\text { Standard NiO } \\
(\text { JCPDS } \\
\text { No. 71-1179) }\end{array}$ & -- & $\begin{array}{c}\text { Cubic } \\
(\text { F.C. })\end{array}$ & 4.178 & 72.92 & -- & 6.80 \\
\hline $\mathrm{NiO}$ & Glycine & $\begin{array}{l}\text { Cubic } \\
(\text { F.C. })\end{array}$ & 4.185 & 73.29 & 28.20 & 7.10 \\
$\mathrm{NiO}$ & Glucose & $\begin{array}{l}\text { Cubic } \\
(\text { F.C. })\end{array}$ & 4.196 & 73.87 & 27.20 & 7.04 \\
$\mathrm{NiO}$ & Urea & $\begin{array}{l}\text { Cubic } \\
\text { (F.C. })\end{array}$ & 4.181 & 73.08 & 28.06 & 7.09 \\
\hline
\end{tabular}


ried out $600^{\circ} \mathrm{C}$. The obtained XRD patterns were compared with the reported standard JCPDS data for NiO (JCPDS card No: 71-1179). The XRD patterns obtained for $\mathrm{NiO}$ (calcined at $600^{\circ} \mathrm{C}$ for $3 \mathrm{~h}$ ) reveal the formation of well-crystallized single phase face centered cubic (FCC) geometry as reported [18]. The XRD peaks of the all the samples are identical with each other. The XRD patterns of each sample exactly agree with the JCPDS data without any collateral peaks, indicating high purity of the prepared samples. The ' $d$ ' values agreed well with the standard values. The lattice parameter is calculated from $2 \theta$ peaks in the X-ray diffraction pattern. The crystallite size of the particles, determined with Scherrer's formula, was found to be in the range of $11-23 \mathrm{~nm}$. Theoretical density values were also agreed well with the reported data. The crystallographic parameters obtained on nickel oxide nanoparticles are indicated in Table 1.

\subsection{Particle size measurements}

The particle size patterns of the $\mathrm{NiO}$ nanoparticles prepared by combustion technique using organic fuels, such as, glycine, glucose and urea respectively are shown in Figure 2 ( $a, b$ and $c)$. For all the measurements, $0.001 \mathrm{~g}$ of $\mathrm{NiO}$ was sonicated in $30 \mathrm{~mL}$ triple distilled water for about 10 minutes and after which the sample was subjected for particle size analysis. The particle characteristics data obtained on nickel oxide nanoparticles particles is indicated in Table 2. From the particle size data (Table 2), it was found that the materials prepared by combustion route using glucose as a fuel resulted in lower particle
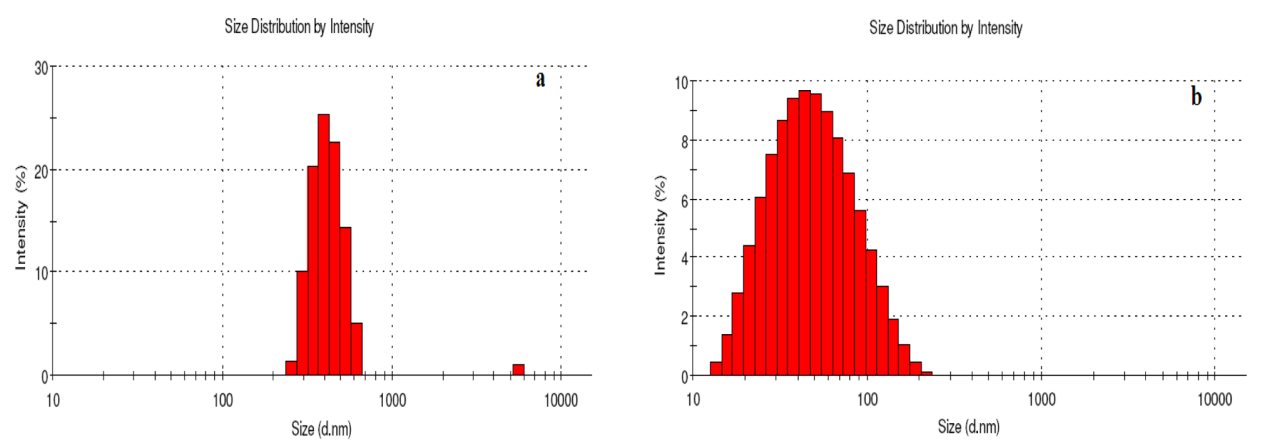

Size Distribution by Intensity

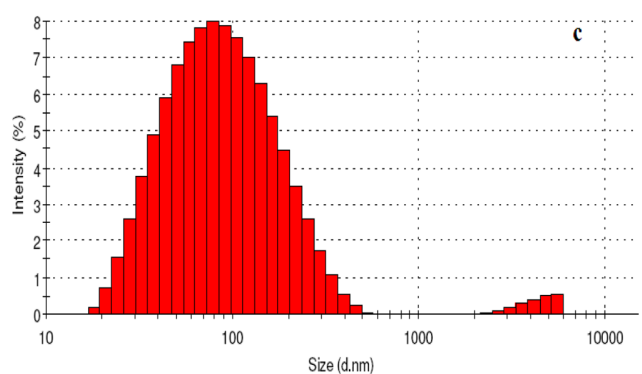

Figure 2. Particle size distribution curves obtained on $\mathrm{NiO}$ nanoparticles prepared by combustion technique using three organic fuels, (a) glycine, (b) glucose and (c) urea.

Table 2. Particle characteristics data obtained on nickel oxide nanoparticles

\begin{tabular}{|c|c|c|c|c|c|c|}
\hline \multirow[b]{2}{*}{ Sample } & \multirow[b]{2}{*}{ Organic Fuel } & \multicolumn{2}{|c|}{ Peak 1} & \multicolumn{2}{|c|}{ Peak 2} & \multirow{2}{*}{$\begin{array}{l}\text { Average } \\
\text { particle size } \\
(\mathrm{nm})\end{array}$} \\
\hline & & $\%$ Intensity & $\begin{array}{l}\text { Diameter } \\
(\mathrm{nm})\end{array}$ & $\%$ Intensity & $\begin{array}{l}\text { Diameter } \\
(\mathrm{nm})\end{array}$ & \\
\hline $\mathrm{NiO}$ & Glycine & 98.9 & 417.9 & 1.1 & 5560 & 480.2 \\
\hline $\mathrm{NiO}$ & Glucose & 100 & 55.71 & -- & -- & 42.23 \\
\hline $\mathrm{NiO}$ & Urea & 97.9 & 104.9 & 2.1 & 4424 & 73.82 \\
\hline
\end{tabular}


size when compared with the samples prepared by other organic fuels. The presence of particles with larger size may be due to the agglomeration effect because of the high temperature calcination process.

\subsection{Scanning electron microscope studies}

The SEM photographs of the NiO nanoparticles prepared by combustion technique using organic fuels, such as, glycine, glucose and urea respectively are shown in Figure 3 ( $a, b$ and c). From the SEM photographs, it was understood that all $\mathrm{NiO}$ grains are spherical in shape. From the figures, it was found that the grains are present in the range of $70-130 \mathrm{~nm}$, $76-115 \mathrm{~nm}$ and $86-180 \mathrm{~nm}$ respectively for the samples prepared by the combustion route using three fuels glycine, glucose and urea. However, the presence of bigger grains in the samples may be due to the high temperature treatment procedure adopted in this research activity.

\subsection{Energy dispersive spectroscopy (EDAX) studies}

The energy dispersive spectra (EDAX) obtained on nickel oxide nanoparticles is reported in Figure 4 (a, $b$ and c). EDAX spectra of the samples show peaks for $\mathrm{Ni}$ and $\mathrm{O}$ only and not for any other impurities in the samples. The chemical composition data obtained on $\mathrm{NiO}$ by EDAX analysis is given in Table 3 . The data confirmed the presence of nickel and oxygen in all the samples. From the EDAX data, it was found that the atomic percentage of nickel is varied between $50-58 \%$ and for oxygen is $41-50 \%$. The variation in the percentage of elements $(\mathrm{Ni}$ and $\mathrm{O}$ ) may be due to the experimental conditions adopted for the preparation of nickel oxide nanoparticles.

\subsection{Cyclic voltammetry studies}

The cyclic voltammetry studies were performed using nickel oxide electrode as working electrode and calomel / platinum wire as reference and counter electrodes respectively in $1 \mathrm{M} \mathrm{KOH}$ electrolyte medium [44]. The CV studies were performed with the scan rate of $1 \mathrm{mVS}^{-1}$ with and the potential range

Table 3. Chemical composition data obtained on nickel oxide nanoparticles by EDAX analysis

\begin{tabular}{cc}
\hline Samples & Atomic $\%$ of elements \\
\hline $\mathrm{NiO}$ (Prepared with glycine) & $\mathrm{Ni}-58.43$ \\
& $\mathrm{O}-41.57$ \\
$\mathrm{NiO}$ (Prepared with glucose) & $\mathrm{Ni}-52.36$ \\
& $\mathrm{O}-47.64$ \\
$\mathrm{NiO}$ (Prepared with urea) & $\mathrm{Ni}-50$ \\
& $\mathrm{O}-50$ \\
\hline
\end{tabular}
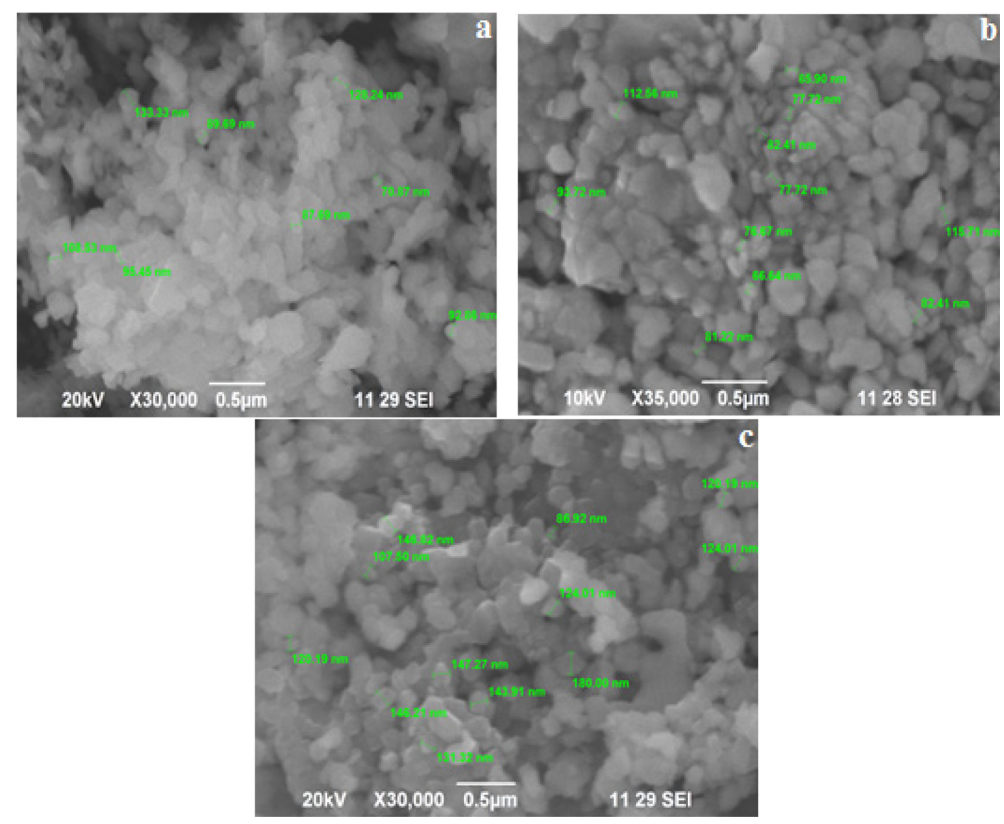

Figure 3. SEM photographs obtained on $\mathrm{NiO}$ nanoparticles prepared by combustion technique using three organic fuels, (a) glycine, (b) glucose and (c) urea. 


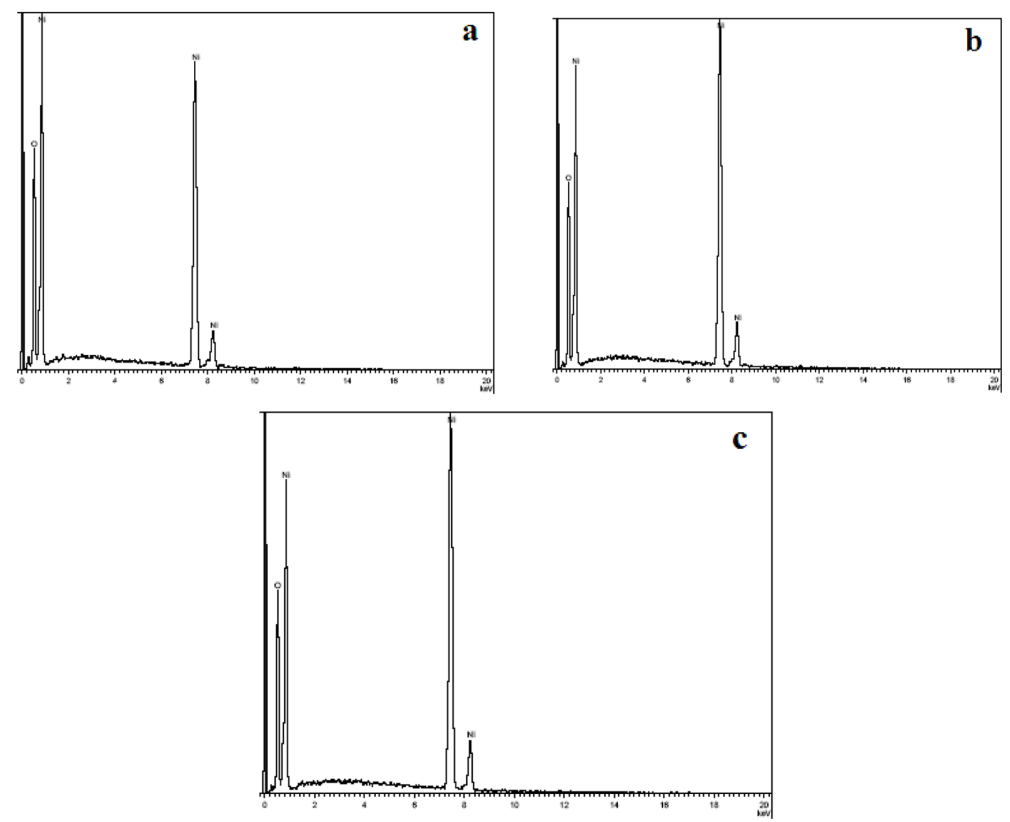

Figure 4. The energy dispersive spectra (EDAX) obtained on $\mathrm{NiO}$ nanoparticles prepared by combustion technique using three organic fuels, (a) glycine, (b) glucose and (c) urea.

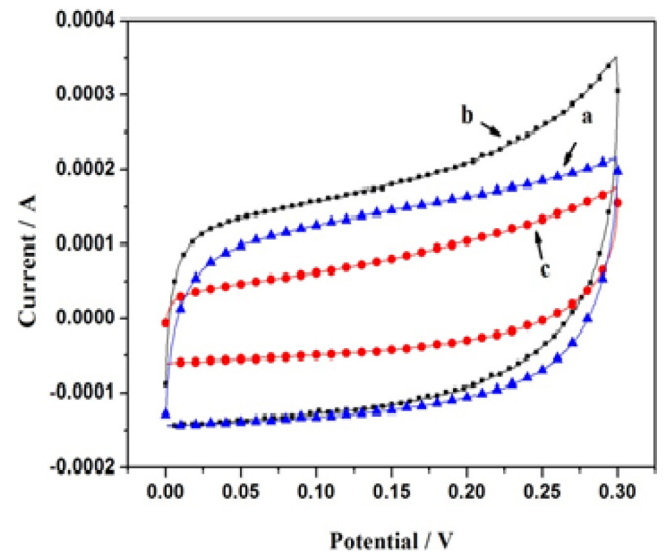

Figure 5. Cyclic voltammograms obtained on $\mathrm{NiO}$ electrode in $1 \mathrm{M} \mathrm{KOH} \mathrm{(a)} \mathrm{NiO}$ prepared with glycine fuel, (b) $\mathrm{NiO}$ prepared with glucose fuel and (c) $\mathrm{NiO}$ prepared with urea fuel.

of 0 to 0.3 volts. The cyclic voltammograms obtained on the $\mathrm{NiO}$ electrode are indicated in Figure $5(\mathrm{a}, \mathrm{b}$ and $\mathrm{c}$ ). The electrochemical reaction of $\mathrm{NiO}$ with the electrolyte can be written as follows:

$$
\mathrm{NiO}+\mathrm{OH}^{-} \leftrightarrow \mathrm{NiO} \| \mathrm{OH}^{-}+\mathrm{NiO}-\mathrm{OH}
$$

Here $\mathrm{NiO} \| \mathrm{OH}^{-}$represents the electric double layer formed by the hydroxyl ion, and $\mathrm{NiO}-\mathrm{OH}$ represent the product formed by the cathode reaction involving the hydroxyl ion [41]. It was found that the observed cyclic voltammograms for all the samples resulted in nearly rectangular shape which may be due to faradaic current [42]. As shown in the curves, there is a pair of strong redox peaks due to a result of the Faradaic reactions of the $\mathrm{NiO}$. It is well known that the Faradaic reaction of the $\mathrm{NiO}$ electrode materials will proceed according to the following reaction [43].

$$
\mathrm{NiO}+\mathrm{OH}^{-} \leftrightarrow \mathrm{NiOOH}+e^{-}
$$

One quasi-reversible electron transfer process is visible in every curve, indicating that the measured capacitance is mainly based on redox mechanism [43]. Besides, the integral area of the CV loops is maximal for the sample prepared with glucose fuel, but minimal for the sample prepared with urea fuel. Also, the shape of the CV curves indicates that the current can quickly reach a plateau value after reversal of the potential sweep. Further, this may be due to the adsorption or desorption of ions according to the applied potential effectively within the electrical double layer at the electrode surface by the electrostatic force. The specific capacitance values calculated for 
Table 4. Specific capacitance (F/g) calculated for nickel oxide electrodes by various electrochemical methods

\begin{tabular}{ccccc}
\hline Working & \multicolumn{3}{c}{ Specific Capacitance (F/g) } \\
\cline { 2 - 5 } Electrode & Cyclic Voltammetry & Impedance Spectroscopy & Chronocoulometry & Average \\
\hline $\begin{array}{c}\text { NiO } \\
\text { (Prepared with glycine) }\end{array}$ & 266.8 & 303.03 & 359.36 & 309.73 \\
NiO & 295.6 & 291.74 & 302.88 & 296.74 \\
$\begin{array}{c}\text { (Prepared with glucose) } \\
\text { NiO }\end{array}$ & 121.29 & 243.6 & 557.28 & 307.39 \\
\hline
\end{tabular}

the samples based on cyclic voltammerty are indicated in Table 4. From the data, it was found that the sample prepared with glucose fuel exhibited better characteristics than the other samples. The remarkable enhancement in the specific capacitance of the $\mathrm{NiO}$ electrodes can mainly be attributed to their specific surface area and smaller pores, which provide effective diffusion channels for the electrolyte ions leading to an improved pseudocapacitive performance as reported [45].

\subsection{Impedance spectroscopic analysis}

The impedance studies were performed using nickel oxide electrode as working electrode and calomel / platinum wire as reference and counter electrodes respectively in $1 \mathrm{M} \mathrm{KOH}$ electrolyte medium. The impedance studies were done with the amplitude of $5 \mathrm{mVS}^{-1}$ and in the frequency range of 1 to $100 \mathrm{mHz}$. The Nyquist plots obtained on $\mathrm{NiO}$ electrode are indicated in Figure $6(\mathrm{a}, \mathrm{b}$ and $\mathrm{c})$. In Figure $6, Z^{\prime}$ and $Z^{\prime \prime}$ indicate the real part and the imaginary part of the impedance. Fitting of the measurement data was performed with the Zview software. The impedance data of the nickel oxide electrode materials is fitted with the equivalent circuit indicated in Figure 7. In Figure 7, the symbol $\rightarrow>$ - referred as constant phase element, $-\mathbf{M r}$ referred as resistor and $\rightarrow-$ referred as Warburg resistance. From the Nyquist plots, it was found that the semicircles were appeared at high frequency range in all the three electrodes studied. In the highto-medium frequency region on semicircle related to Faradaic reactions can be discovered, which should be attributed to the charge transfer resistance at the electrode/electrolyte interface [26,47]. The plots indicated in Figure 6 consists of semicircles and incline straight lines which could be represented by three distinct regions within the studied

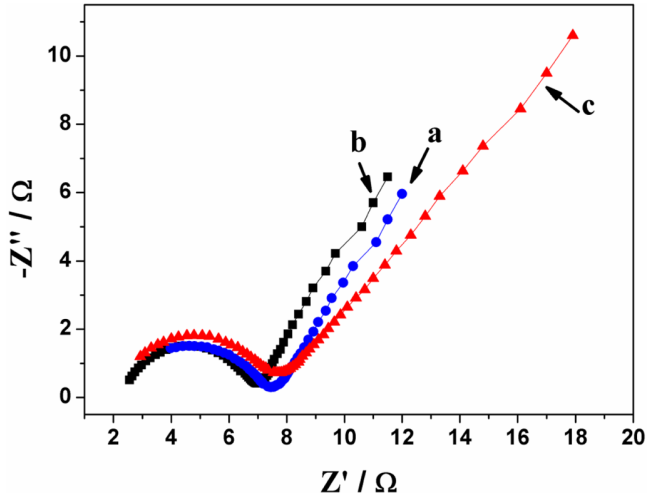

Figure 6. Nyquist plots obtained on $\mathrm{NiO}$ electrode in $1 \mathrm{M}$ $\mathrm{KOH}$ (a) $\mathrm{NiO}$ prepared with glycine fuel, (b) $\mathrm{NiO}$ prepared with glucose fuel and (c) $\mathrm{NiO}$ prepared with urea fuel.

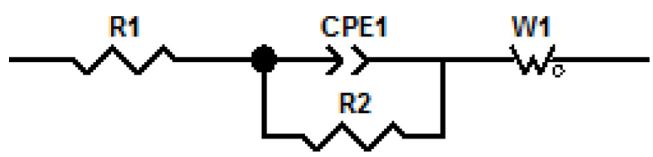

Figure 7. Equivalent circuit, used to fit measurement data obtained on nickel oxide electrode materials.

frequency range. A pure capacitance behavior $\left(C_{d l}\right)$ is represented in low frequency region in which a drastic increment of the imaginary part with an almost vertical line is observed. A slope close to $45^{\circ}$ in the middle frequency range indicates the existence of Warburg impedance (W) involving the diffusion characteristic of the electrolyte into electrodes. It is believed that ion adsorption process becomes more active as the frequency decreases due to there is ample of time for the electrolyte species to enter to the deeper region of the of the porous structure of the electrodes. In the high frequency range, semicircles are observed in the plots and this corresponded to the charge-transfer process at the electrode / electrolyte interface [40]. Therefore, 
the appearance of solution resistance or electrolyte resistance $(\mathrm{Re})$ and the particle resistance $(\mathrm{Rp})$ in the system resulted in semicircle of the Nyquist plot at high frequency region. The specific capacitance values calculated in the low frequency region of the Nyquist plots based on impedance analysis for the samples are indicated in Table 6. From the data, it was found that the electrode prepared with glycine as a fuel exhibited better characteristics than the other samples.

\subsection{Chronocoulometry studies}

It is one of the classical technique frequently used in electro analytical chemistry. As, its name implies, choronocoulometry is the measurement of charge (coulombs) as a function of time (Chrono). The chronocoulometry studies were performed using nickel oxide electrode, calomel / platinum wire as reference and counter electrodes respectively in $1 \mathrm{M} \mathrm{KOH}$ electrolyte medium. The chronocoulometry studies were carried out in the voltage range of 0 to $0.25 \mathrm{~V}$ in $1 \mathrm{M} \mathrm{KOH}$ solution. The chronocoulometry curves obtained on the $\mathrm{NiO}$ electrode are indicated in Figure 8 ( $\mathrm{a}, \mathrm{b}$ and $\mathrm{c}$ ). The specific capacitance values calculated for the samples based on chronocoulometry analysis are indicated in Table 6. From the data, it was found that the electrode prepared with urea as a fuel exhibited better characteristics than the other samples. However, the capacitance value obtained for $\mathrm{NiO}$ electrodes prepared with urea fuel is found to be different from other techniques.

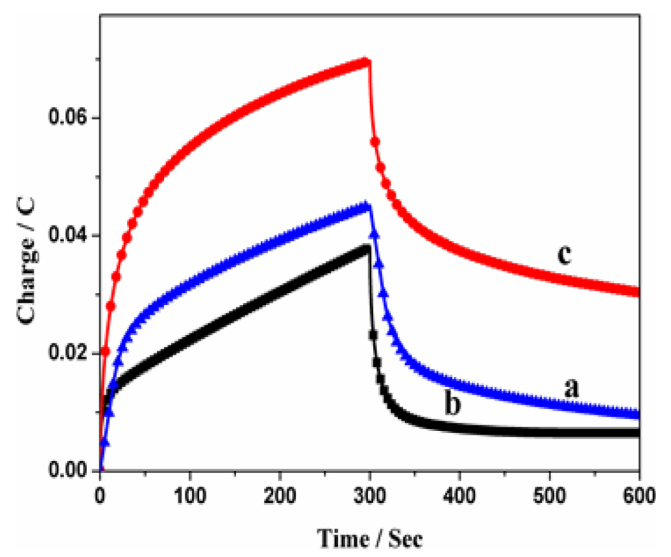

Figure 8. Chronocoulometry curves obtained on $\mathrm{NiO}$ electrode in $1 \mathrm{M} \mathrm{KOH} \mathrm{(a)} \mathrm{NiO}$ prepared with glycine fuel, (b) $\mathrm{NiO}$ prepared with glucose fuel and (c) $\mathrm{NiO}$ prepared with urea fuel.
From the electrochemical characterization of $\mathrm{NiO}$ electrode materials, the nanoparticles prepared by combustion route have resulted in good capacitance values applicable for electrochemical capacitors. Also, it was found that that specific capacitance obtained for the $\mathrm{NiO}$ electrode prepared with glucose as organic fuel exhibited a uniform specific capacitance values measured in all the three electrochemical techniques. This may be due to lower particle size and better stability of the electrode samples in the operating conditions.

\section{Conclusions}

Wet chemical synthesis of nickel oxide nanoparticles by combustion technique using three organic fuels, viz., glycine, glucose and urea is reported in this research article. The powder XRD data of the samples is well matched with the reported JCPDS data. Particle size data inferred the presence of nanoparticles along with few larger sized particles in the samples. The surface morphological analysis confirmed the presence of spherical shaped nanoparticles in the samples. The presence of atomic elements such as $\mathrm{Ni}$ and $\mathrm{O}$ in the required percentage is confirmed by EDAX data. The electrochemical studies such as, cyclic voltammetry, impedance analysis and choronocoulometry studies carried out on the nickel oxide electrodes revealed better characteristics for all the samples. However, among the three systems studied, the nickel oxide nanoparticles prepared by combustion route using glucose as an organic fuel resulted in stable capacitance values. All the three samples studied are suitable for electrochemical capacitor applications.

\section{Acknowledgement}

ASN thanks Karunya University for promoting nanoelectrochemistry research activity. GS thanks University Grants Commission (UGC, Government of India) for providing Rajiv Gandhi Fellowship for Students with Disability (No. F./2013-14/RGNF2013-14D-O BC-TAM-56465) to carry out the research work in Karunya University.

\section{References}

[1] E.H. Liu, W. Li, J. Li, X.Y. Meng, R. Ding and S.T. Tan, Mater. Res. Bull., 44, 1122 (2009) 
[2] M.D. Stoller and R.S. Ruoff, Energy Environ. Sci., 3, 1294 (2010)

[3] E. Kim, D. Son, T.G. Kim, J. Cho, B. Park, K.S. Ryu and S.H. Chang, Angew. Chem. Int. Ed., 43, 5987 (2004).

[4] X.W. Lou, D. Deng, J.Y. Lee and L.A. Archer, J. Mater. Chem., 18, 4397 (2008).

[5] X.W. Lou, D. Deng, J.Y. Lee, J. Feng and L.A. Archer, Adv. Mater., 20, 258 (2008).

[6] Z.Z. Lin, F.L. Jiang, L. Chen, C.Y. Yue, D.Q. Yuan, A.J. Lan and M.C. Hong, Cryst. Growth Des. 7, 1712 (2007).

[7] Y. Wan and D. Zhao, Chem. Rev. 107, 2821 (2007).

[8] Q. Zhao, Z. Zhang, T. Dong and Y. Xie, J. Phys. Chem. $B, \mathbf{1 1 0}, 15152$ (2006).

[9] G.A. Seisenbaeva, M.P. Moloney, R. Tekoriute, A.H. Dessources, J.M. Nedelec, Y. K. Gun'ko, Vadim G. Kessler, Langmuir 26, 9809 (2010).

[10] Zhongli Wang, Ruixia Liu, Fengyu Zhao, Xiaojuan Liu, Minfeng Lv and Jian Meng, Langmuir, 26, 10135 (2010).

[11] A.Z. Sadek, H. Zheng, M. Breedon, V. Bansal, S.K. Bhargava, K. Latham, J. Zhu, L. Yu, Z. Hu, P.G. Spizzirri, W. Wlodarski and K. K. Zadeh, Langmuir, 25, 9545 (2009).

[12] D.B. Robinson, C.A.M. Wu, M.D. Ong, B.W. Jacobs and B.E. Pierson, Langmuir 26, 6797 (2010).

[13] T. Stimpfling and F. Leroux, Chem. Mater., 22, 974 (2010).

[14] D. Carriazo, F. Picó, M.C. Gutiérrez, F. Rubio, J.M. Rojo and F. D. Monte, J. Mater. Chem. 20, 773 (2010).

[15] K. Wang, Y. Wang, Y. Wang, E. Hosono and H. Zhou, J. Phys. Chem. C, 113, 1093 (2009).

[16] G.M. Suppes, B.A. Deore and M.S. Freund, Langmuir, 24, 1064 (2008).

[17] Q. Cheng, J. Tang, J. Ma, H. Zhang, N. Shinya and L.C. Qin, Carbon, 49, 2917 (2011).

[18] B.T. Raut, S.G. Pawar, M.A. Chougule, Shaswati Sen and V.B. Patil, J Alloys and Compounds, 509, 9065 (2011).

[19] M. Hasan, M.Jamal and K.M. Razeeb, Electrochimica Acta, 60,193 (2012).

[20] J.P. Zheng and T.R. Jow, J. Electrochem. Soc., 142, L6 (1995).

[21] J.P. Zheng, P.J. Cygan and T.R. Jow, J. Electrochem. Soc. 142, 2699 (1995).

[22] C.C. Hu and Y. H. Huang, J. Electrochem. Soc. 146, 2495 (1999).

[23] Y. Zhang, G.Y. Li, Y. Lv, L.Z. Wang, A.Q. Zhang, Y.H. Song and B.L. Huang, J. Hydrogen Energy, 36, 11760 (2011).

[24] K.R. Prasad and N. Miura, Electrochem. Commun. 6, 1004 (2004).

[25] J. Yan, T. Wei, J. Cheng, Z. Fan and M. Zhang, Mater. Res. Bull. 45, 210 (2010).
[26] J. Xu, L. Gao, J. Cao, W. Wang and Z. Chen, Electrochimica Acta, 56, 732 (2010).

[27] Q. Yuanchun, Z. Yanbao and W. Zhishen, Mater. Chem. Phy., 110, 457 (2008).

[28] Y.Y. Ping, L.R. Sheng, H.K. Long, W.L. Ping, L.S. Qin and Z.W. Wen, Trans. Non ferrous Met. Soc. China, 17, 1334 (2007).

[29] K.C. Stella and A.S. Nesaraj, Iranian J. Materials Science \& Engineering, 7, 36 (2010).

[30] G. Mattei, P. Mazzoldi, M.L. Post, D. Buso, M. Guglielmi and A. Martucci, J. Adv. Materials, 19, 561 (2007).

[31] M.W. Zhu, Z.J. Wang, Y.N. Chen and Z.D. Zhang, Surface \& Coatings Tech. 216, 139 (2013).

[32] K.O. Moura, R.J.S. Lima, C.B.R. Jesus, J.G.S. Duque and C.T. Meneses, Revista Mexicana de F'lsica, S 58, 167 (2012).

[33] F. Davar, Z. Fereshteh and M.S. Niasari, J. Alloys and Compounds, 476, 797 (2009).

[34] S.A.E. Safty, M. Khairy, M. Ismael and H. Kawarada, Applied Catalysis B: Environmental, 123-124, 162 (2012).

[35] F. Lin, M. Montano, C. Tian, Y. Ji, D. Nordlund, T.C. Weng, R.G. Moore, D.T. Gillaspie, K.M. Jones, A.C. Dillon, R.M. Richards and C. Engtrakul, Solar Energy Materials and Solar Cells, 126, 206 (2014).

[36] B. Vidhyadharan, N.K.M. Zain, I.I. Misnon, R.A. Aziz, J. Ismail, M.M. Yusoff and R. Jose, J. Alloys and Compounds, 610, 143 (2014).

[37] A. Jena, N. Munichandraiah and S.A. Shivashankar, $J$. Power Sources, 237, 156 (2013).

[38] D.W. Wang, F. Li and H.M. Cheng, J. Power Sources, 185, 1563 (2008).

[39] L. Feng, Y. Zhu, H. Ding, C. Ni, J. Power Sources, 267, 430 (2014).

[40] S.K. Chang, Z. Zainal, K.B. Tan, N. A.Yusof, W.M.D. Wan Yusoff and S.R.S. Prabaharan, Current Appl. Phy., 12, 1421 (2012).

[41] R.R. Salunkhe, K. Jang, H. Yu, S. Yu, T. Ganesh, S.H. Han and H. Ahn, J. Alloys and Compounds, 509, 6677 (2011).

[42] J.Y. Choi and J.H. Choi, J. Indust. Engg. Chem., 16, 401 (2010).

[43] H.Y. Wu and H.W. Wang, Int. J. Electrochem. Sci., 7, 4405 (2012).

[44] W.H. Zhu, J.J. Ke, H.M. Yu and D.J. Zhang, J. Power Sources, 56, 75 (1995).

[45] X. Zhang, W. Shi, J. Zhu, W. Zhao, J. Ma, S. Mhaisalkar, T.L. Maria, Y. Yang, H. Zhang, H.H. Hng and Q. Yan, Nano Res., 3, 643 (2010).

[46] E. Frackowiak and F. Beguin, Carbon, 39, 937(2001).

[47] J.L. Liu, L.Z. Fan and X. Qu, Electrochimica Acta, 66, 302 (2012). 